\title{
Activity as a proxy to estimate metabolic rate and to partition the metabolic cost of diving vs. breathing in pre- and post-fasted Steller sea lions
}

\author{
A. Fahlman ${ }^{1, *}$, C. Svärd ${ }^{2}$, D. A. S. Rosen ${ }^{3}$, R. P. Wilson ${ }^{4}$, A. W. Trites ${ }^{3}$ \\ ${ }^{1}$ Department of Life Sciences, Texas A\&M University-Corpus Christi, 6300 Ocean Drive, Unit 5800, Corpus Christi, \\ Texas 78412, USA \\ ${ }^{2}$ Swedish Museum of Natural History, Box 50007, S-10405 Stockholm, Sweden \\ ${ }^{3}$ Marine Mammal Research Unit, Fisheries Centre, Room 247, AERL, University of British Columbia, Vancouver, BC, \\ Canada, V6T 1Z4 \\ ${ }^{4}$ Biosciences, College of Science, Swansea University, Swansea SA2 8PP, Wales, UK
}

\begin{abstract}
Three Steller sea lions Eumetopias jubatus, trained to dive voluntarily to depths ranging from 10 to $50 \mathrm{~m}$, were used to determine whether the relationship between activity and metabolic rate during a diving interval $\left(\mathrm{MR}_{\mathrm{DI}}\right.$, dive + surface interval) was affected by fasting (9 $\left.\mathrm{d}\right)$ during the breeding season (spring through summer). We subsequently used the relationship between activity and $\mathrm{MR}_{\mathrm{DI}}$ to partition the metabolic costs between underwater breath-holding activity and surface breathing activities. We estimated activity from overall dynamic body acceleration (ODBA) measured using a 3-axis accelerometer, and measured $\mathrm{MR}_{\mathrm{DI}}$ using flow-through respirometry. The relationship between ODBA-based activity and $\mathrm{MR}_{\mathrm{DI}}$ was not affected by fasting period, suggesting that ODBA can be used to predict energy expenditure regardless of nutritional state in the spring and summer. However, the relationship between ODBA and dive metabolic rate differs from the relationship between ODBA and the surface metabolic rate before diving. Partitioning $\mathrm{MR}_{\mathrm{DI}}$ into the metabolic cost of remaining at the surface versus swimming underwater suggests that the metabolic cost of diving for Steller sea lions is approximately $29 \%$ lower than when breathing at the surface. ODBA appears to be a reasonable proxy to estimate metabolic rate in marine mammals, but more detailed behavioral data may be required to accurately apply the method in the field.
\end{abstract}

KEY WORDS: Marine mammal $\cdot$ Breath-hold diving $\cdot$ Field energetics $\cdot$ ODBA Resale or republication not permitted without written consent of the publisher

\section{INTRODUCTION}

Several methods have been developed to estimate the at-sea metabolic rates of diving animals (Butler et al. 2004, Fahlman et al. 2004, Wilson et al. 2006). One of these methods, the doubly labeled water (DLW) method, yields the average energy expended by an animal over a finite time, but cannot determine the metabolic cost for different activities such as diving or swimming at the surface (but see Nagy et al. 1984). Another technique uses heart rate as a proxy of energy expenditure (Butler et al. 2004), but is difficult to apply because the relationship between the rate of $\mathrm{O}_{2}$ consumption and heart rate, or $\mathrm{O}_{2}$ pulse $\left(\mathrm{ml} \mathrm{O}_{2}\right.$ heart beat ${ }^{-1}$ ), changes with digestive state and different types and levels of activity (Nolet et al. 1992, Fahlman et al. 2004, Young et al. 2011a,b). A recent alternative method for estimating at-sea metabolism, overall dynamic body acceleration (ODBA), relies on the relationship between energy expenditure and activity measured using 3-axis accelerometers (Wilson et al. 2006, Gleiss et al. 2011), and appears be a useful proxy to estimate the energetic cost of diving in marine mammals (Fahlman et al. 2008c). 
Properly controlled calibration studies are required before any method to estimate metabolic rates can be used to reliably predict field metabolic rates (Fahlman et al. 2004). Such calibration studies typically entail comparing the metric under consideration with measured oxygen consumption rates $\left(\dot{V}_{\mathrm{O}_{2}}\right)$, often with captive animals studied under controlled conditions. While logistical constraints prevent testing all plausible scenarios that might occur in the wild, it is important to incorporate a reasonable range of activities (e.g. rest, exercise on land, swimming in water, diving) and physiological states (e.g. nutritional and digestive status) into the design of calibration experiments.

Calibration studies in breath-hold diving vertebrates are challenging because of the temporal discontinuity that occurs between energy used while submerged and gas exchanged while the animal is at the surface. There is also the added complication that the series of dives occurring during a foraging bout are often not independent of each other because diving animals incur an $\mathrm{O}_{2}$ debt when making repeated dives with short inter-dive surface intervals (Reed et al. 1994, Boutilier et al. 2001, Fahlman et al. 2008b). Consequently, experimental designs where the $\mathrm{O}_{2}$ debt is not accounted for between dives cannot correctly estimate the metabolic cost of a dive interval, and may result in erroneous conclusions. Correcting for such errors can be done through proper experimental design and data treatment, such as constraining the surface interval until the $\mathrm{O}_{2}$ debt is paid back to make each dive independent.

We previously showed that activity levels measured by ODBA correlate well with metabolic rate for Steller sea lions Eumetopias jubatus diving freely to depths ranging between 10 and $50 \mathrm{~m}$ (Fahlman et al. 2008c). However, we did not consider whether the relationship was affected by variation in nutritional status of the sea lions, which might induce changes in metabolism (increased activity in water or metabolic depression) or thermoregulatory costs (through decreased insulation; Hind \& Gurney 1997, Fahlman et al. 2005). We therefore expanded our previous study of Steller sea lions to address whether the relationships between ODBA and the metabolic rate during a complete dive interval $\left(\mathrm{MR}_{\mathrm{DI}}\right.$; the metabolic rate for one dive, dive + surface interval) differed before (pre-fasted) and during recovery from a $9 \mathrm{~d}$ fast (post-fasted) during the breeding season in Steller sea lions. We focused on the summer period as Steller sea lions generally do not fast in the winter months and long-term fasting generally occurs during the breeding season (Rea et al. 2009). We also investi- gated whether the relationship between activity and metabolic rate was similar during diving and while breathing at the surface, and compared the metabolic cost of diving with the costs of remaining on the surface, as well as with Kleiber's prediction for basal metabolic rate (BMR).

\section{MATERIALS AND METHODS}

The experiments and procedures used to measure the metabolic rate during a $\mathrm{MR}_{\mathrm{DI}}$ (in previous studies called DMR) and ODBA are as described by Fahlman et al. (2008c) and Svärd et al. (2009), and are briefly summarized below. All acceleration and respirometry data from 2 summer fasting protocols (Fasts 1 and 2) are described by Svärd et al. (2009), and were compared with a subset (April until October 2007) of the activity and respirometry data of fed sea lions from an earlier study (Fahlman et al. 2008c).

\section{Animals}

All experiments were conducted under permits from Animal Care Committees of the University of British Columbia and the Vancouver Aquarium. Experiments were conducted between April and October 2007 with 3 female Steller sea lions housed in a custom-designed floating net pen $(3.6 \times 3.6 \times 6.1 \mathrm{~m})$ suspended in seawater approximately $1.5 \mathrm{~m}$ deep with a haul-out space, located in a coastal inlet in British Columbia, Canada. The sea lions freely chose to cooperate with all data collection and were never restrained during any of the experimental trials. Body mass $\left(M_{\mathrm{b}} \mathrm{kg}\right.$ ) was measured daily before each dive trial and was measured opportunistically throughout the fasting periods (depending on animal cooperation) by having the animals hold position on a platform scale $( \pm 0.5 \mathrm{~kg})$ prior to any feeding.

\section{Experimental objectives}

The experiments consisted of a series of pre- and post-fasting dive trials to determine the effect of fasting on the relationship between ODBA and $\mathrm{MR}_{\mathrm{DI}}$. To ensure that the sea lions were not naïve to the required dive parameters during a dive trial, each animal was trained to dive to the required depth for 5 to $7 \mathrm{~d}$ prior to collecting any data (see 'Experimental procedure and measuring diving oxygen consumption'). In addition to these training dives, the sea lions 
had extensive experience undertaking dive trials to similar depths during previous studies (Fahlman et al. 2008a,b). The duration of the fasting period was designed to result in a total mass loss of $\sim 10 \%$ of the initial $M_{\mathrm{b}}$, but not exceeding $15 \%$ (as per Animal Care protocols). All dive trials were performed in the morning, at least 16 to $20 \mathrm{~h}$ (pre-fast experiments) and up to $216 \mathrm{~h}$ (post-fast experiments) since their last meal.

\section{Fasting conditions}

Data to assess the effect of recovery from an extended fast were obtained for the summer trials from a previously published study (Svärd et al. 2009). The experiment consisted of a series of dive trials (10 to $50 \mathrm{~m}$ ) during pre-fasting conditions or following a fasting period of 9 to $10 \mathrm{~d}$ (Fasts 1 and 2) and again during a subsequent 2 wk recovery period during which 5 post-fast dive trials were conducted at predetermined intervals (Post-fast 1: $0 \mathrm{~d}$, Post-fast 2: 12 d; Post-fast 3: 4-5 d, Post-fast 4: 7-8 d, and Post-fast 5: 12-13 d after the end of the fast; Svärd et al. 2009). The dive trials included dives to depths between 10 and $50 \mathrm{~m}$, depending on the willingness of the individual sea lion (Table 1).

\section{Experimental procedure and measuring diving oxygen consumption}

The different measures of metabolic rate (detailed below) were estimated from $\dot{V}_{\mathrm{O}_{2}}$ using flow-through respirometry as previously detailed (Fahlman et al. 2008b,c, Svärd et al. 2009). While the fractional concentrations of both $\mathrm{O}_{2}$ and $\mathrm{CO}_{2}$ were used to estimate

Table 1. Eumetopias jubatus. Number of dives made to different dive depths $(\mathrm{m})$ for 3 female Steller sea lions (F00BO, F97SI and F97HA) during pre-fasting and post-fasting experiments in summer. nd: no data; N/A: dive depth not known

\begin{tabular}{|lccccccccc|}
\hline \multirow{2}{*}{ Animal } & \multicolumn{10}{c|}{ Depth $(\mathrm{m})$} & & & \\
\cline { 2 - 9 } & 0 & 10 & 15 & 20 & 30 & 40 & 50 & N/A \\
\hline Pre-fast & & & & & & & & \\
F00BO & 11 & 18 & nd & 3 & 1 & nd & 22 & nd \\
F97SI & 8 & 32 & 4 & 3 & 19 & nd & nd & nd \\
F97HA & 7 & 16 & 3 & nd & 4 & 2 & 18 & nd \\
& & & & & & & & \\
Post-fast & & & & & & & & \\
F00BO & 5 & 8 & nd & nd & 4 & 2 & 9 & 3 \\
F97SI & 4 & 13 & nd & nd & 15 & nd & nd & nd \\
F97HA & 4 & 14 & nd & 3 & 4 & 1 & 6 & nd \\
\hline
\end{tabular}

$\dot{V}_{\mathrm{O}_{2}}$ and $\dot{V}_{\mathrm{CO}_{2}}$ as previously described (Fahlman et al. $2008 \mathrm{~b})$, only the former is reported here in keeping with our objective to determine the relationship between $\dot{V}_{\mathrm{O}_{2}}$ and ODBA.

Prior to the daily trials, each sea lion was weighed and fitted with a webbing body harness that held an accelerometer (see below) and a VHF transmitter (used to locate the sea lion in the event of it leaving the trial area).

Prior to and between dives, each sea lion was held in a partially submerged cage with access to fresh air in a respirometry dome floating at the water surface, allowing the sea lion to breathe while in the water (Fahlman et al. 2008b,c, Svärd et al. 2009). The cage made it possible to contain the sea lion for a period long enough to assure a stable metabolic measurement (pre-dives) and that the post-dive metabolic rate had returned to the level before diving such that the $\mathrm{O}_{2}$ debt had been repaid (Fahlman et al. 2008b). While the animals were within the cage, their activity varied between surface periods between dives. This activity included short (10-15 s) shallow (1-2 m) dives as the animal submerged and sat on the door at the bottom of the cage, swimming and turning. As the sea lions had extensive experience with the dome and the cage and as they were never forced to enter the dome on days when they did not want to participate, it is unlikely that these activities were signs of stress. Our values were therefore, by definition, neither resting nor basal estimates of metabolic rate, but rather an estimate for an animal with varying activity levels at the surface which we previously have defined as surface metabolic rate $\left(\mathrm{MR}_{\mathrm{Si}}\right.$ Fahlman et al. 2008b,c, Svärd et al. 2009).

Our sea lions were encouraged to remain active at a pre-determined depth by providing them with an artificial prey field. This was done using a tube and pump system to deliver fish ( $20 \mathrm{~g}$ segments of previously frozen herring) to depth at a constant rate ( 0 to 12 fish pieces $\mathrm{min}^{-1}$ or between 0 and $240 \mathrm{~g} \mathrm{~min}^{-1}$, Fahlman et al. 2008b,c, Svärd et al. 2009). The activity varied between sea lions and trials as the underwater current and visibility differed between experimental trial dates. This served to increase the range of activity levels tested.

For a dive trial, the sea lion was instructed to enter the respirometry dome and the cage door was closed. The animal stayed in the dome for 6 min to measure the pre-dive surface metabolic rate $\left(\mathrm{MR}_{\mathrm{Sp}}\right.$ Fig. 1). The last $2 \mathrm{~min}$ of this period were used to estimate $\mathrm{MR}_{\mathrm{Sp}}$, and the duration was extended if steady values of $\mathrm{O}_{2}$ and $\mathrm{CO}_{2}$ were not recorded during the last $2 \mathrm{~min}$. The sea lions had not been fed for at least $16 \mathrm{~h}$ 


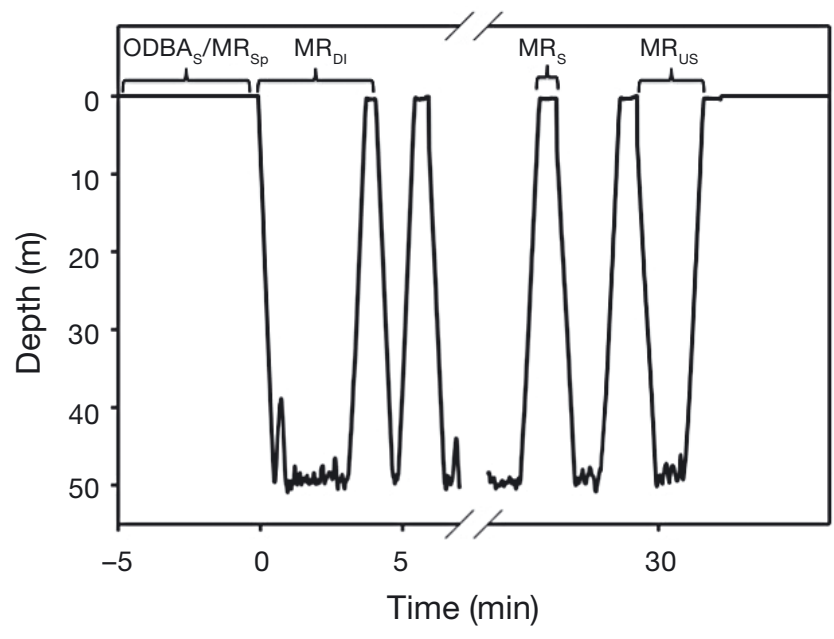

Fig. 1. Eumetopias jubatus. Representative dive bout with a total of 8 dives to $50 \mathrm{~m}$ for Steller sea lion FA97HA used to show how the dive experiment was divided up into discrete units for further analysis. $\mathrm{ODBA}_{\mathrm{s}}$ is the overall dynamic body acceleration for the surface period, $\mathrm{MR}_{\mathrm{Sp}}$ is the predive surface metabolic rate, $\mathrm{MR}_{\mathrm{S}}$ is the surface metabolic rate between dives, $M R_{D I}$ is the diving metabolic rate for a dive interval (dive + subsequent surface interval) and $M R_{U S}$ the estimated metabolic cost for under water swimming. $M R_{\mathrm{DI}}=M R_{\mathrm{S}}+\mathrm{MR}_{\mathrm{US}}$

for the $\mathrm{MR}_{\mathrm{Sp}}$ measurements, but the activity inside the dome was highly variable.

Each sea lion was instructed to swim to the end of the feeding tube that was placed at a predetermined depth $(10,15,20,30,40$ or $50 \mathrm{~m})$. The duration of a dive was determined by the sea lion. To assure that the sea lion would not resume a dive with an $\mathrm{O}_{2}$ or $\mathrm{CO}_{2}$ debt, the sea lion was held in the dome between repeated dives until the metabolic rate had returned to pre-dive levels (between 6 and 8 min; Fahlman et al. 2008b,c, Svärd et al. 2009). As our previous data showed that digestion could affect the metabolic rate in nutritionally compromised sea lions (Fahlman et al. 2008b,c, Svärd et al. 2009), the metabolic rate during the surface period between dives $\left(\mathrm{MR}_{\mathrm{S}}\right)$ was distinguished from $\mathrm{MR}_{\mathrm{Sp}}$. In other words, $\mathrm{MR}_{\mathrm{Sp}}$ was the first surface period before an animal had eaten or performed any dives, while $\mathrm{MR}_{\mathrm{S}}$ was the metabolic rate between dives in a dive bout (Fig. 1). The sequence of a dive and surface interval was repeated for between 1 and 12 dives during each trial (1 trial per day).

The average $\dot{V}_{\mathrm{O}_{2}}$ for each dive and subsequent surface interval (1 dive interval) was estimated by integrating the instantaneous oxygen consumption rate over the entire post-dive surface interval (the entire surface duration between dives) and dividing this by the dive interval duration (Fahlman et al. 2008b,c,
Svärd et al. 2009). In other words, we used an entire dive interval (dive + surface interval) to estimate $M_{\mathrm{DI}}$. All surface intervals in a dive series were $>240 \mathrm{~s}$. We also restricted the analysis to dives $>30 \mathrm{~s}$.

The water temperatures at the surface and at the end of the feeding tube were monitored during each trial using remote temperature loggers (Onset Computer). Water temperatures at the surface ranged from 6.0 to $16.8^{\circ} \mathrm{C}$, while temperatures at depth $(1$ to $50 \mathrm{~m}$ ) ranged from 7.9 to $12.0^{\circ} \mathrm{C}$, with one summer dive trial when the water temperature was $17.3^{\circ} \mathrm{C}$ at depth. Water temperatures were quite variable, but were all within or close to the presumed thermoneutral zone for fasted or post-prandial Steller sea lions (Rosen \& Trites 2003).

\section{Estimating activity from acceleration}

An accelerometer (JUV Elektronik; $65 \times 36 \times$ $22 \mathrm{~mm}$, mass $35 \mathrm{~g}$ ) that recorded triaxial acceleration $(0$ to $6 \times g)$ at $16 \mathrm{~Hz}$ was attached to the sea lion's harness so that it lay centrally between the shoulder blades. The logger was calibrated by rotating the unit through defined combinations of pitch and roll, and converting all voltages to $g$.

ODBA $(g)$ was estimated as described in Wilson et al. (2006). Briefly, the static acceleration for each axis was derived by taking a running mean over a $2 \mathrm{~s}$ interval (Shepard et al. 2008). Subsequently, the static acceleration, or smoothed data, was subtracted from the raw data, resulting in an estimate of dynamic acceleration. In other words, the gravity resulting from the relative position of the data logger was removed from the data such that the resulting value only related to the movement of the animal. Finally, the absolute value for the dynamic acceleration for each of the 3 axes was summed to give ODBA, a measure of activity. We used the average ODBA for the dive and subsequent surface interval (dive interval) to compute an average activity for the dive interval. We also calculated ODBA for just the pre-dive surface period $\left(\mathrm{ODBA}_{\mathrm{S}}\right)$ to examine the relationship between $\dot{V}_{\mathrm{O}_{2}}$ and activity during this period.

\section{Data assessment and statistical analysis}

We analyzed the relationship between $\dot{V}_{\mathrm{O}_{2}}$ (dependent variable) and 7 experimental covariates using linear-mixed effects models (nlme; R Development Core Team 2008): ODBA; fasting state (FS), where 
$1=$ post-fasted and $0=$ pre-fasted $;$ surface interval (SI); dive duration (DD); dive depth (D); $M_{\mathrm{b} i}$ the number of days since the beginning of the fast; ${ }_{\text {; }}$ and surface interval ratio (SR). Animal was included as a random effect, which accounted for the correlation between repeated measurements on the same individual (Littell et al. 1998).

All animals had not been fed for 16 to $20 \mathrm{~h}$ (prefasted), including when they were tested at various intervals over a $2 \mathrm{wk}$ recovery from a $9 \mathrm{~d}$ fast (postfasted). As Svärd et al. (2009) showed that the metabolic rate changes over the course of the recovery period, we initially tested whether number of days since the end of the fast was an important covariate. However, this variable did not significantly improve any of the models and was therefore not further considered. As there is a non-linear relationship between metabolic rate and $M_{\mathrm{b}}$, we $\log _{10}$-transformed $\mathrm{MR}_{\mathrm{Sp}}\left(\log \mathrm{MR}_{\mathrm{Sp}}\right), \mathrm{MR}_{\mathrm{S}}\left(\log \mathrm{MR}_{\mathrm{S}}\right), \mathrm{MR}_{\mathrm{DI}}\left(\log \mathrm{MR}_{\mathrm{DI}}\right)$ and $M_{\mathrm{b}}\left(\log M_{\mathrm{b}}\right)$ to test for mass-specific changes in $\dot{V}_{\mathrm{O}_{2}}$ with $M_{\mathrm{b}}$. As $\mathrm{MR}_{\mathrm{DI}}$ included the metabolic rate during both the surface and dive interval, we calculated SR to indicate the relative proportion of time a sea lion stayed at the surface during a dive interval. SR was computed by dividing the SI by the total dive interval duration $(\Sigma \mathrm{DD})$ :

$$
\mathrm{SR}=\mathrm{SI} / \Sigma \mathrm{DD}
$$

Initially, a univariate analysis on each independent variable was performed, and only those variables with $\mathrm{p}<0.20$ (Wald's tests) were considered in the multivariate analysis. Stepwise techniques were used to search for the best model. We used the likelihood ratio test to determine significance of parameters between nested models, i.e. models with added parameters. Acceptance of significance was set at $\mathrm{p}<$ 0.05 , and $0.05<\mathrm{p}<0.1$ was considered to be important enough to warrant further investigation. All values are reported as means \pm SD unless otherwise specified.

\section{RESULTS}

The number of surface resting periods, dives to a specified depth, and mean dive durations are summarized in Table 2 . The mean dive duration decreased as the animals dove deeper for dives between 10 and $30 \mathrm{~m}$, but increased for dives beyond $30 \mathrm{~m}$.

\section{Effect of fasting on metabolic rate}

While there was no difference in $\mathrm{MR}_{\mathrm{Sp}}$ in postfasted as compared with pre-fasted animals $(\mathrm{p}>0.1$; Table 2), $\mathrm{MR}_{\mathrm{DI}}$ decreased by $7 \%$ (post-fasted, $\mathrm{n}=82$, $1.45 \pm 0.03 \mathrm{l} \mathrm{O}_{2} \mathrm{~min}^{-1}$; pre-fasted, $\mathrm{n}=145,1.55 \pm 0.03$ $\left.1 \mathrm{O}_{2} \min ^{-1} ; \mathrm{p}<0.05\right)$. Hence, $\mathrm{MR}_{\mathrm{DI}}$ was on average $17 \%$ greater than $\mathrm{MR}_{\mathrm{Sp}}$ in pre-fasted animals $\left(\left[\mathrm{MR}_{\mathrm{DI}}-\mathrm{MR}_{\mathrm{Sp}}\right] / \mathrm{MR}_{\mathrm{DI}}, \mathrm{F} 97 \mathrm{SI}=13 \%\right.$, F97HA $=19 \%$, $\mathrm{F} 00 \mathrm{BO}=18 \%$ ), while $\mathrm{MR}_{\mathrm{DI}}$ was $10 \%$ greater than $\mathrm{MR}_{\mathrm{Sp}}$ in post-fasted individuals (F97SI $=10 \%$, $\mathrm{F} 97 \mathrm{HA}=4 \%, \mathrm{~F} 00 \mathrm{BO}=15 \%$ ).

Predicting the BMR $\left(\mathrm{l} \mathrm{O}_{2} \mathrm{~min}^{-1}\right)$ for each data point using Kleiber's equation $\left(\mathrm{BMR}=0.00993 M_{\mathrm{b}}^{0.75}\right.$; Kleiber 1961, Wang et al. 2001) and dividing the observed MR by this predicted BMR (Table 2) yielded an average Kleiber ratio $(K)$ of 3.1 for all data. Maximum $K$ was 4.9 for a sea lion during a pre-dive

Table 2. Eumetopias jubatus. Dive depth, total number of dives to a known depth (n, in parentheses the number of dives post-fast) and mean $( \pm \mathrm{SD})$ dive duration, metabolic rate (MR), overall dynamic body acceleration (ODBA), and Kleiber ratio ( $K$, estimated by dividing the observed MR by Kleiber's basal metabolic rate) separated by dive depth for a total of 227 dives with available data for MR and ODBA. For 3 dives, the dive depth was uncertain (N/A); therefore, only 224 dives were available with known depth. The MR at depth is the metabolic rate for a dive interval $\left(\mathrm{MR}_{\mathrm{DI}}\right)$ while the $\mathrm{MR}$ at $0 \mathrm{~m}$ is the pre-dive surface metabolic rate $\left(\mathrm{MR}_{\mathrm{Sp}}\right)$

\begin{tabular}{|c|c|c|c|c|c|c|c|c|c|}
\hline \multirow{2}{*}{$\begin{array}{l}\text { Dive depth } \\
\text { (m) }\end{array}$} & \multirow[t]{2}{*}{$\mathrm{n}$} & \multicolumn{2}{|c|}{ Dive duration (min) } & \multicolumn{2}{|c|}{$-\operatorname{MR}\left(\mathrm{l} \mathrm{O}_{2} \min ^{-1}\right)-$} & \multicolumn{2}{|c|}{ ODBA $(g)-$} & \multirow{2}{*}{$\overline{\text { Pre-fast }}$} & \multirow{2}{*}{$K$ Post-fast } \\
\hline & & Pre-fast & Post-fast & Pre-fast & Post-fast & Pre-fast & Post-fast & & \\
\hline 0 & 39 (13) & - & - & $1.38 \pm 0.38$ & $1.21 \pm 0.36$ & $0.16 \pm 0.06$ & $0.17 \pm 0.06$ & $2.9 \pm 0.6$ & $2.7 \pm 0.5$ \\
\hline 10 & $101(35)$ & $2.6 \pm 1.3$ & $2.6 \pm 1.1$ & $1.60 \pm 0.31$ & $1.51 \pm 0.25$ & $0.23 \pm 0.05$ & $0.24 \pm 0.05$ & $3.3 \pm 0.4$ & $3.2 \pm 0.4$ \\
\hline 15 & $7(0)$ & $1.5 \pm 0.8$ & - & $1.74 \pm 0.45$ & - & $0.21 \pm 0.05$ & - & $3.5 \pm 0.4$ & - \\
\hline 20 & $9(3)$ & $2.0 \pm 0.5$ & $2.7 \pm 1.9$ & $1.74 \pm 0.26$ & $1.15 \pm 0.23$ & $0.24 \pm 0.02$ & $0.24 \pm 0.03$ & $3.5 \pm 0.2$ & $2.7 \pm 0.6$ \\
\hline 30 & $47(23)$ & $2.5 \pm 1.3$ & $3.1 \pm 1.4$ & $1.76 \pm 0.23$ & $1.61 \pm 0.30$ & $0.24 \pm 0.05$ & $0.26 \pm 0.09$ & $3.3 \pm 0.4$ & $3.3 \pm 0.3$ \\
\hline 40 & $5(3)$ & $6.0 \pm 0.3$ & $2.1 \pm 0.5$ & $1.37 \pm 0.02$ & $1.25 \pm 0.16$ & $0.28 \pm 0.02$ & $0.21 \pm 0.03$ & $3.0 \pm 0.1$ & $3.1 \pm 0.2$ \\
\hline 50 & 55 (15) & $4.2 \pm 1.4$ & $4.6 \pm 1.1$ & $1.29 \pm 0.22$ & $1.20 \pm 0.12$ & $0.20 \pm 0.05$ & $0.21 \pm 0.05$ & $3.0 \pm 0.5$ & $3.1 \pm 0.3$ \\
\hline N/A & $3(3)$ & - & $1.2 \pm 0.1$ & - & $1.12 \pm 0.11$ & - & $0.19 \pm 0.01$ & - & $2.9 \pm 0.3$ \\
\hline$\Sigma$ & 266 & & & & & & & & \\
\hline
\end{tabular}


surface period $\left(\mathrm{MR}_{\mathrm{Sp}}\right)$, while the minimum $K$ of 1.9 was observed both during a pre-dive surface $\left(\mathrm{MR}_{\mathrm{Sp}}\right)$ period and during a dive interval to $50 \mathrm{~m}$.

The mean $M_{\mathrm{b}}$ was $174.6 \pm 4.4 \mathrm{~kg}(\mathrm{n}=54)$, and postfasted sea lions $(165.3 \pm 4.2 \mathrm{~kg}, \mathrm{n}=18)$ were $7.8 \%$ lighter than pre-fasted animals $(179.2 \pm 5.1 \mathrm{~kg}, \mathrm{n}=$ $36, p<0.05$, repeated-measures ANOVA). Including $M_{\mathrm{b}}$ as a covariate was sufficient to account for the metabolic variation following fasting. The mass exponent (the slope from the regression of $\log \mathrm{MR}_{\mathrm{DI}}$ vs. $\log M_{\mathrm{b}}$ ) from the regression analysis was not different from 1.0 during a dive interval $\left(\log \mathrm{MR}_{\mathrm{DI}}\right.$, $0.97 \pm 0.12$ ), but was significantly higher and much more variable during surface rest periods $\left(\log M R_{\mathrm{Sp}}\right.$, $1.33 \pm 0.35)$.

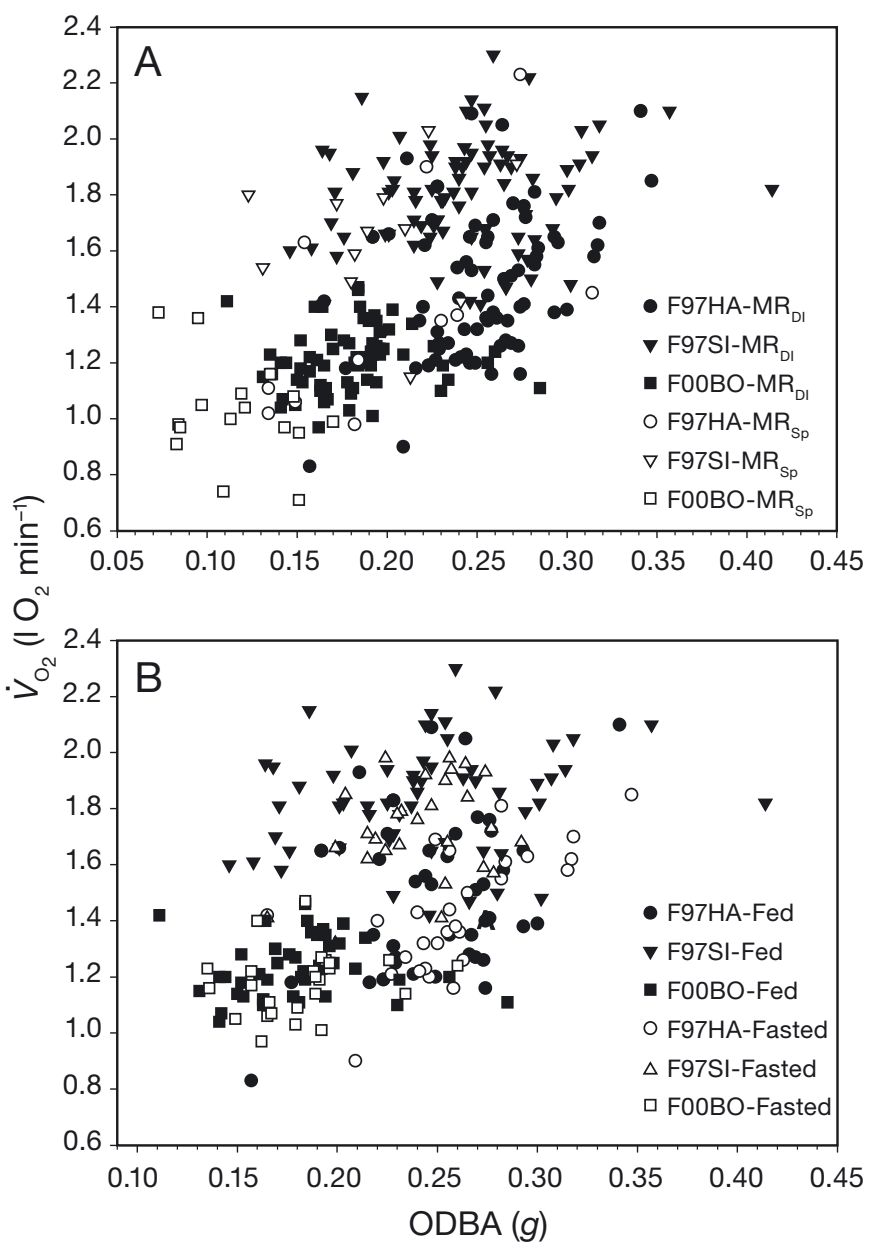

Fig. 2. Eumetopias jubatus. Overall dynamic body acceleration (ODBA) versus $\mathrm{O}_{2}$ consumption rate $\left(\dot{V}_{\mathrm{O}_{2}}\right)$ for 3 Steller sea lions (F97SI, F97HA and F00BO) during a dive interval $\left(\mathrm{MR}_{\mathrm{DI}}=\right.$ metabolic rate during the dive and consecutive surface interval) or while confined to the metabolic dome at the surface before diving $\left(\mathrm{MR}_{\mathrm{Sp}}=\right.$ pre-diving surface metabolic rate). (A) Pre- and post-fasted trials separated into $M R_{D I}$ and $\mathrm{MR}_{\mathrm{Sp} i}(\mathrm{~B}) \mathrm{MR}_{\mathrm{DI}}$ separated into pre- and post-fasted trials

\section{Relationship between $\dot{V}_{\mathrm{O}_{2}}$ and ODBA}

Pre-dive surface rest $\left(\mathrm{MR}_{\mathrm{Sp}}\right)$

There was a total of 39 pre-dive resting periods (Table 2) in the data set, one for each dive trial. The average $\mathrm{ODBA}_{\mathrm{S}}$ was $0.17 \mathrm{~g}$ (range 0.07 to $0.31 \mathrm{~g}$ ). These data were used to determine whether there was a significant relationship between $M_{\mathrm{Sp}}$ and ODBA $_{S}$ (Fig. 2A). Neither FS nor SI were important covariates when $\log \mathrm{MR}_{\mathrm{Sp}}$ was used as the dependent variable. The best model included both $\log M_{\mathrm{b}}$ and ODBA $_{S}(\mathrm{p}<0.01, \log$-likelihood [LL] $=-34.6, \mathrm{df}=36$, NULL-LL $=-40.5, \mathrm{df}=38)$ :

$$
\log \mathrm{MR}_{\mathrm{Sp}}=-2.14+0.97 \log \mathrm{M}_{\mathrm{b}}+0.55 \mathrm{ODBA}_{\mathrm{S}}
$$

The basal metabolic rate for a sea lion in air, as predicted by Kleiber's law (Kleiber 1961), would be $0.48 \mathrm{l} \mathrm{O}_{2} \mathrm{~min}^{-1}$ for a $175 \mathrm{~kg}$ animal $\left(2.7 \mathrm{ml} \mathrm{O}_{2} \mathrm{~min}^{-1}\right.$ $\mathrm{kg}^{-1}$ ), assuming a mixed diet in which $1 \mathrm{lO}_{2}=$ $4.9 \mathrm{kcal}$. If the minimum measured $\mathrm{ODBA}_{\mathrm{S}}(0.07 \mathrm{~g})$ is an estimate of a resting sea lion that has not been eating for at least $16 \mathrm{~h}$, Eq. (2) predicts the metabolic rate for a $175 \mathrm{~kg}$ sea lion in water to be $1.19 \mathrm{l} \mathrm{O}_{2}$ $\mathrm{min}^{-1}$, or $6.8 \mathrm{ml} \mathrm{O}_{2} \mathrm{~min}^{-1} \mathrm{~kg}^{-1}$.

\section{Dive interval metabolic rate $\left(\mathrm{MR}_{\mathrm{DI}}\right)$}

A total of 227 dives (Tables 1 \& 2) were analyzed separately to assess the relationship between $\mathrm{MR}_{\mathrm{DI}}$ and mean ODBA over a dive interval. The mean ODBA over an entire dive interval (dive + surface interval) was $0.23 \pm 0.01 \mathrm{~g}$ (minimum: $0.11 \mathrm{~g}$, maximum: $0.65 \mathrm{~g}$ ), and did not differ between post-fasted $(0.22 \pm 0.02 \mathrm{~g})$ and pre-fasted $(0.23 \pm 0.01 \mathrm{~g}, \mathrm{p}>0.1)$ sea lions. ODBA decreased with dive depth $(\mathrm{p}<0.01$, $\mathrm{LL}=-321.3, \mathrm{df}=222, \mathrm{NULL}-\mathrm{LL}=-328.5, \mathrm{df}=223)$, but was not affected by dive duration $(\mathrm{p}>0.1, \mathrm{LL}=$ $-329.1, \mathrm{df}=225$, NULL-LL $=-330.6, \mathrm{df}=226$; Fig. 2 ).

With $\log \mathrm{MR}_{\mathrm{DI}}$ as the dependent variable, the bestfit model included SR, $\log M_{\mathrm{b}}$ and ODBA $(\mathrm{p}<0.01$, $\mathrm{LL}=-321.1, \mathrm{df}=220, \mathrm{NULL}-\mathrm{LL}=-344.0, \mathrm{df}=226$ ) such that:

$\log \mathrm{MR}_{\mathrm{DI}}=-3.27+1.46 \log M_{\mathrm{b}}+0.35 \mathrm{ODBA}+0.15 \mathrm{SR}$

The mean error ([observed-predicted]/observed $x$ 100) for the data set was $-0.3 \%$ with a range from -52.6 to $32.0 \%$ (median $2.1 \%$ ). There was no difference in the error with fasting state (post-fasted: $1.4 \%$, pre-fasted: $-0.3 \%, \mathrm{p}>0.1, t$-test). Furthermore, a sensitivity analysis was performed where the 
data for each animal were removed sequentially and the model was fitted. The analysis suggested that the same model was warranted but had slightly different parameter estimates.

Eq. (3) suggests that the metabolic cost of a dive interval is affected by the relative amount of time within the cycle spent at the surface versus the amount of time spent actively diving. Further, by adjusting SR between its boundary values (0 to 1 ), Eq. (3) allows $M R_{D I}$ to be partitioned into the separate metabolic costs of surface intervals and the metabolic cost while submerged. Using the mean ODBA for a dive interval (post-fasted and pre-fasted: 0.23 ) and an $M_{\mathrm{b}}$ of $175 \mathrm{~kg}$, the cost of time at the surface during a dive interval $\left(\mathrm{MR}_{\mathrm{S}}\right.$, when $\left.\mathrm{SR}=1\right)$ would be $1.721 \mathrm{O}_{2}$ $\min ^{-1}\left(9.8 \mathrm{ml} \mathrm{O}_{2} \mathrm{~min}^{-1} \mathrm{~kg}^{-1}\right)$. Given the same level of activity, the metabolic cost of diving $(\mathrm{SR}=0)$, in contrast, may be as much as $29 \%$ lower $\left(7.0 \mathrm{ml} \mathrm{O}_{2} \mathrm{~min}^{-1}\right.$ $\mathrm{kg}^{-1}$ ) and was similar to that predicted for $\mathrm{MR}_{\mathrm{Sp}}$.

\section{DISCUSSION}

Our results suggest that ODBA-based activity is a reasonable proxy to estimate field metabolic rate in marine mammals, both while resting at the surface and while diving to depths for durations that are similar to those measured from Steller sea lions in the field (Merrick \& Loughlin 1997, Pitcher et al. 2005). The predictive relationship between $\dot{V}_{\mathrm{O}_{2}}$ and ODBA did not change after a 9-d fasting period during the breeding season, and $M_{\mathrm{b}}$ appears to be sufficient to statistically account for the metabolic changes associated with fasting. However, our results also illustrate that the ability to predict energy expenditure is dependent on the characteristics of the dive interval, since the relationships predicting metabolism at the surface and the costs of diving from ODBA are not the same. Similar divergence in the relationship for different activities has been found by others (Gómez Laich et al. 2011). Therefore, additional behavioral information is required to appropriately use ODBA data to predict $\dot{V}_{\mathrm{O}_{2}}$ in the field. Specifically, the time spent diving versus time spent resting at the surface is required to calculate the surface interval ratio. Fortunately, such data are readily obtained from a variety of electronic instruments that can be attached to marine mammals to record time and depth.

Partitioning $\mathrm{MR}_{\mathrm{DI}}$ into the metabolic cost of staying at the surface (MRs) versus underwater swimming $\left(\mathrm{MR}_{\mathrm{US}}\right)$ showed that, for the same activity, the metabolic cost of diving is approximately $29 \%$ lower than when breathing at the surface (Eq. 3), and approximately 2.4 to 2.9 times higher than the basal metabolic rate from Kleiber's equation. The fact that physical movement requires energy is not a novel concept. Indeed, a number of recent studies have investigated ways in which activity might be used to estimate $\dot{V}_{\mathrm{O}_{2}}$ under a variety of situations (e.g. walking vs. running) or environments (e.g air, land or water, Gleiss et al. 2011). To our knowledge, only 3 studies have investigated whether ODBA can be used to estimate the metabolic cost of diving in vertebrates (Fahlman et al. 2008c, Enstipp et al. 2011, Halsey et al. 2011), but no attempts have been made to determine whether the relationship is altered by changes in $M_{\mathrm{b}}$ owing to a previous fast.

Our analysis shows that ODBA correlates reasonably well with $\mathrm{MR}$, and that the relationship is not altered by fasting, unlike the heart rate technique (Fahlman et al. 2004, Young et al. 2011a). This is not surprising, given that the dynamic body acceleration is derived specifically from the extent and rates of body part movements, which are presumably similar in both post-fasted and pre-fasted animals during swimming (Gleiss et al. 2011). Previous studies in Steller sea lions have shown a substantial decrease in metabolism following fasting (Rosen \& Trites 2002, Fahlman et al. 2004, Svärd et al. 2009), possibly as a mechanism to conserve energy stores. In addition, subcutaneous fat is a major source of energy during fasting (Rea et al. 2007, Rea et al. 2009), and diving vertebrates appear to have strategies to compensate for the loss of the insulating layer (Fahlman et al. 2005). Therefore, we wanted to determine whether these potential changes in physiology and metabolism would affect the relationship. Our results indicated that fasting and recovery of body condition did not affect the relationship.

It is reasonable to assume that fasting affects the ability to thermoregulate (Hind \& Gurney 1997), given the associated decrease in subcutaneous lipid stores (Rea et al. 2007). Potential thermoregulatory effects for the relationship between diving metabolism and ODBA may be largest in the winter, or for species that live or forage at high latitudes. As we were unable to collect acceleration data for animals recovering from a fasting period in the winter, we cannot reject the possibility that thermoregulation alters the relationship during parts of the year or in environments that are colder than those used in our study. However, long-term fasting generally occurs during the breeding season, and Steller sea lions generally do not fast in the winter months (Rea et al. 2009). In addition, both marine mammals (Willis et al. 
2005) and birds (Fahlman et al. 2005) have mechanisms to alter heat flux, which may help compensate for reduced blubber insulation.

In addition, a reduction in capillary density or muscle mass, which may occur during substantive fasting (Robin et al. 1988), may alter the swimming efficiency, with resulting changes in the relationship between ODBA and MR. However, the results from our study did not indicate that this was the case, as $M_{\mathrm{b}}$ alone accounted for most of the fasting-related variation, perhaps because the extent of fasting in our study animals did not lead to significant reduction in muscle mass or thermoregulatory capacity. Alternatively, the fasting-induced reduction in MR may have been counteracted by an increased thermoregulatory burden during underwater swimming in post-fasted animals. It is also possible that the low variation in the water temperature, in most cases $<5^{\circ} \mathrm{C}$ between pre- and post-fast trials, was not great enough to affect the relationship. While fasting appears to have a greater physiological effect on sea lions in the non-breeding season (Svärd et al. 2009), Steller sea lions have an easier time recovering from changes in body condition in the winter compared with the summer (Jeanniard du Dot et al. 2008). Given these different responses between seasons, it would be interesting to repeat these experiments during winter.

Previous results suggested that there was no statistical difference in the relationships between ODBA and $\mathrm{MR}_{\mathrm{Sp}}$, and ODBA and $\mathrm{MR}_{\mathrm{DI}}$ (Fahlman et al. 2008c). This finding significantly enhanced the applicability of ODBA, as the predictive relationship could be calibrated for animals at the water surface. However, the results of our current study indicate that the parameter estimate for ODBA is $40 \%$ lower for $\mathrm{MR}_{\mathrm{DI}}$ $\left(\mathrm{ODBA}=0.35\right.$, Eq. 3) as compared with $\mathrm{MR}_{\mathrm{Sp}}$ (ODBA $=0.55$, Eq. 2).

Our modified analytic approach to account for variation in $M_{\mathrm{b}}$ does not explain why the results of our 2 studies differ given that the difference remains when we analyzed the data using the methodology of our previous study (see Appendix 1). Instead, it seems that the more extensive data set used here $(\mathrm{n}=266$ dives compared with 144 in the previous study) was able to separate the differences in the relationship. In addition, Eq. (3) indicated that for the same ODBA and $M_{\mathrm{b}}$, the metabolic cost for sea lions during a dive interval was up to $29 \%$ lower for $\mathrm{MR}_{\mathrm{US}}$ as compared with resting at the surface $\left(\mathrm{MR}_{\mathrm{S}}\right)$.

We previously used a conservative mass exponent $(0.75)$ to account for variation in MR caused by differences in $M_{\mathrm{b}}$ for nourished sea lions (Fahlman et al. 2008c, Svärd et al. 2009). However, in the present study, we avoided any potential bias from using a pre-determined mass exponent (Packard \& Boardman 1988,1999$)$ by $\log _{10}$-transforming $M_{\mathrm{b}}$ and including it as a fixed factor (Eqs. 2,3). The mass exponent for $\log \mathrm{MR}_{\mathrm{DI}}$ (Eq. 3) was significantly larger compared with $\log \mathrm{MR}_{\mathrm{Sp}}$ (Eq. 2). These results are counter-intuitive, as they suggest that it is metabolically more challenging for larger animals to dive. However, Eq. (3) includes SR and this ratio may be correlated with $M_{\mathrm{b}}$ and ODBA, thereby affecting the mass exponent. In any case, $M_{\mathrm{b}}$ alone explained the variation caused by the fasting period (Eqs. 2 and 3).

The combination of metabolic heat production, convective heat loss and hydrodynamic drag is complex. Modeling work has suggested that as the swim speed increases the metabolic heat production would increase faster than the convective heat loss (Hind \& Gurney 1997). This may explain, in part, why the MR during a dive interval was higher at the surface than during diving. It is also possible that other mechanisms, either behavioral or physiological, allow Steller sea lions to reduce the metabolic rate while diving. Steller sea lions glide passively as they descend beyond $5 \mathrm{~m}$, and swim actively during the ascent phase (see Fig. 3 in Fahlman et al. 2008c). This propulsion mode has been suggested to be a costsaving strategy employed by marine mammals (Williams 1999), and is one possible explanation for MR being low while submerged. In other words, the animals were more active while at the surface than while underwater. However, when the variation in activity is taken into consideration, $\mathrm{MR}_{\mathrm{US}}$ was still lower than $\mathrm{MR}_{\mathrm{S}}$, suggestive of hypometabolism while diving.

It has been suggested that pinnipeds may reduce their overall metabolic rate during longer dives to extend aerobic dive duration. Such hypometabolism has been reported previously for both forced and voluntarily diving seals (Scholander 1940, Sparling \& Fedak 2004) and California sea lions (Hurley \& Costa 2001). Voluntary diving gray seals Halichoerus grypus showed a 10 to $30 \%$ reduction in MR (Sparling \& Fedak 2004), and in California sea lions Zalophus californianus trained to rest at the bottom of a pool, the decrease was 47 to $65 \%$ (Hurley \& Costa 2001). This reduction could be achieved by minimizing energy cost from certain metabolic processes such as digestion (Sparling et al. 2007, Svärd et al. 2009), and diving bradycardia may reduce cardiac work and thereby the overall MR by as much as $6 \%$ (Fahlman et al. 2008c). While the mechanism of such hypometabolism is currently unknown, it is known that 
hypoxia itself causes a reduction in ATP utilization (Hochachka 1986), which may explain why the metabolic cost of swimming underwater is lower than the cost of swimming at the surface.

In the present study, we used a conservative estimate of the resting metabolic rate to define divinginduced hypometabolism and only included the predive surface rest periods to define $\mathrm{MR}_{\mathrm{Sp}}$. In contrast, $\mathrm{MR}_{\mathrm{S}}$ in our previous study (Fahlman et al. 2008c), included all pre-dive and inter-dive surface resting periods. Thus, $\mathrm{MR}_{\mathrm{Sp}}$ in the present study was a true estimate of the metabolic rate of an animal that has not recently been feeding. We found that $\mathrm{MR}_{\mathrm{DI}}$ was 6 to $15 \%$ higher than $\mathrm{MR}_{\mathrm{Sp}}$, and was at least 1.9 times the predicted BMR from Kleiber's equation (Table 2). However, $\mathrm{MR}_{\mathrm{DI}}$ was likely over-estimated given that the surface interval was metabolically more costly and the duration at the surface was experimentally determined.

Eq. (3) allows $M R_{D I}$ to be extrapolated for dive intervals with different surface ratios. $\mathrm{MR}_{\mathrm{DI}}$ for a Steller sea lion would thus range between 7.0 and $7.2 \mathrm{ml} \mathrm{O} \mathrm{min}^{-1} \mathrm{~kg}^{-1}$ for a $175 \mathrm{~kg}$ sea lion with the average activity of $0.23 \mathrm{~g}$ and a voluntarily foraging surface ratio between 0.01 and 0.09 (Cornick et al. 2006, Fahlman et al. 2008c). This value of $M_{\mathrm{DI}}$ is similar to $\mathrm{MR}_{\mathrm{Sp}}$.

Similar to our earlier findings, the metabolic cost of diving is similar to the resting surface metabolic rate under standard conditions. In addition, our data indicate that OBDA is a useful proxy for field metabolic rate in Steller sea lions, but that adjustments must be made to account for the 2 different relationships between ODBA and MR - one when the animal is at the surface and another while it is diving. Determining surface and dive times can be easily calculated from time-depth recorders that are simultaneously deployed with accelerometers. Fortunately, nutritional status did not seem to affect the predictive relationships between ODBA and MR. Indeed, most of the variation in the relationship was caused by differences in body condition and was explained by $M_{\mathrm{b}}$ alone. However, both the surface resting and diving metabolic rates are $\sim 2.5$ times higher than the basal metabolic rate predicted by Kleiber's equation for terrestrial animals in air.

Acknowledgements. Funding was provided to the North Pacific Universities Marine Mammal Research Consortium by the North Pacific Marine Science Foundation and the US National Oceanographic and Atmospheric Administration. We especially thank the technical and administrative staff, and the trainers at the UBC Open Water Research Lab and the Vancouver Aquarium.

\section{LITERATURE CITED}

Boutilier RG, Reed JZ, Fedak MA (2001) Unsteady-state gas exchange and storage in diving marine mammals: the harbor porpoise and gray seal. Am J Physiol 281: R490-R494

Butler PJ, Green JA, Boyd IL, Speakman JR (2004) Measuring metabolic rate in the field: the pros and cons of the doubly labelled water and heart rate methods. Funct Ecol 18:168-183

Cornick LA, Inglis SD, Willis K, Horning M (2006) Effects of increased swimming costs on foraging behavior and efficiency of captive steller sea lions: evidence for behavioral plasticity in the recovery phase of dives. J Exp Mar Biol Ecol 333:306-314

Enstipp MR, Ciccione S, Gineste B, Milbergue M and others (2011) Energy expenditure of freely swimming adult green turtles (Chelonia mydas) and its link with body acceleration. J Exp Biol 214:4010-4020

Fahlman A, Handrich Y, Woakes AJ, Bost CA, Holder R, Duchamp C, Butler PJ (2004) Effect of fasting on the $\mathrm{VO}_{2}-f_{\mathrm{h}}$ relationship in king penguins, Aptenodytes patagonicus. Am J Physiol 287:R870-R877

Fahlman A, Schmidt A, Handrich Y, Woakes AJ, Butler PJ (2005) Metabolism and thermoregulation during fasting in king penguins, Aptenodytes patagonicus, in air and water. Am J Physiol 289:R670-R679

- Fahlman A, Hastie GD, Rosen DAS, Naito Y, Trites AW (2008a) Buoyancy does not affect diving metabolism during shallow dives in steller sea lions Eumetopias jubatus. Aquat Biol 3:147-154

Fahlman A, Svärd C, Rosen DAS, Jones DR, Trites AW (2008b) Metabolic costs of foraging and the management of $\mathrm{O}_{2}$ and $\mathrm{CO}_{2}$ stores in steller sea lions. J Exp Biol 211: 3573-3580

Fahlman A, Wilson R, Svärd C, Rosen DAS, Trites AW (2008c) Activity and diving metabolism correlate in steller sea lion Eumetopias jubatus. Aquat Biol 2:75-84

Gleiss AC, Wilson RP, Shepard ELC (2011) Making overall dynamic body acceleration work: on the theory of acceleration as a proxy for energy expenditure. Methods Ecol Evol 2:23-33

> Gómez Laich A, Wilson RP, Gleiss AC, Shepard ELC, Quintana F (2011) Use of overall dynamic body acceleration for estimating energy expenditure in cormorants. Does locomotion in different media affect relationships? J Exp Mar Biol Ecol 399:151-155

- Halsey LG, Jones TT, Jones DR, Liebsch N, Booth DT (2011) Measuring energy expenditure in sub-adult and hatchling sea turtles via accelerometry. PLoS ONE 6:e22311

$>$ Hind AT, Gurney WS (1997) The metabolic cost of swimming in marine homeotherms. J Exp Biol 200:531-542

> Hochachka PW (1986) Metabolic arrest. Intensive Care Med 12:127-133

> Hurley JA, Costa DP (2001) Standard metabolic rate at the surface and during trained submersions in adult California sea lions (Zalophus californianus). J Exp Biol 204: 3273-3281

Jeanniard du Dot T, Rosen DAS, Trites AW (2008) Steller sea lions show diet-dependent changes in body composition during nutritional stress and recover more easily from mass loss in winter than in summer. J Exp Mar Biol Ecol 367:1-10

Kleiber M (1961) The fire of life: an introduction to animal energetics. Wiley, New York, NY 
Littell RC, Henry PR, Ammerman CB (1998) Statistical analysis of repeated measures data using sas procedures. J Anim Sci 76:1216-1231

Merrick RL, Loughlin TR (1997) Foraging behavior of adult female and young-of-the-year Steller sea lions in Alaskan waters. Can J Zool 75:776-786

Nagy KA, Siegfried WR, Wilson RP (1984) Energy utilization by free-ranging jackass penguins, Spheniscus demersus. Ecology 65:1648-1655

Nolet BA, Butler PJ, Masman D, Woakes AJ (1992) Estimation of the daily energy expenditure from heart rate and doubly labelled water in exercising geese. Physiol Zool 65:1188-1216

Packard GC, Boardman TJ (1988) The misuse of ratios, indexes, and percentages in ecophysiological research. Physiol Zool 61:1-9

Packard GC, Boardman TJ (1999) The use of percentages and size-specific indices to normalize physiological data for variation in body size: wasted time, wasted effort? Comp Biochem Physiol 122:37-44

Pitcher KW, Rehberg MJ, Pendleton GW, Raum-Suryan KL, Gelatt TS, Swain UG, Sigler MF (2005) Ontogeny of dive performance in pup and juvenile Steller sea lions in alaska. Can J Zool 83:1214-1231

R Development Core Team (2008) R: A language and environment for statistical computing. R Foundation for Statistical Computing, Vienna

> Rea LD, Rosen DAS, Trites AW (2007) Utilization of stored energy reserves during fasting varies by age and season in Steller sea lions. Can J Zool 85:190-200

Rea LD, Berman-Kowalewski M, Rosen DA, Trites AW (2009) Seasonal differences in biochemical adaptation to fasting in juvenile and subadult Steller sea lions (Eumetopias jubatus). Physiol Biochem Zool 82:236-247

Reed JZ, Chambers C, Fedak MA, Butler PJ (1994) Gas exchange of captive freely diving grey seals (Halichoerus grypus). J Exp Biol 191:1-18

Robin JP, Frain M, Sardet C, Groscolas R, Le Maho Y (1988) Protein and lipid utilization during long-term fasting in emperor penguins. Am J Physiol 254:R61-R68

Rosen DAS, Trites AW (2002) Changes in metabolism in response to fasting and food restriction in the Steller sea lion. Comp Biochem Physiol B 132:389-399
Rosen DAS, Trites AW (2003) No evidence for bioenergetic interaction between digestion and thermoregulation in Steller sea lions Eumetopias jubatus. Physiol Biochem Zool 76:899-906

Scholander PF (1940) Experimental investigations on the respiratory function in diving mammals and birds. Hvalrådets Skrifter 22:1-131

Shepard ELC, Wilson RP, Halsey LG, Quintana F and others (2008) Derivation ofbody motion via appropriate smoothing of acceleration data. Aquat Biol 4:235-241

Sparling CE, Fedak MA (2004) Metabolic rates of captive grey seals during voluntary diving. J Exp Biol 207: 1615-1624

Sparling CE, Fedak MA, Thompson D (2007) Eat now, pay later? Evidence of deferred food-processing costs in diving seals. Biol Lett 3:95-99

Svärd C, Fahlman A, Rosen DAS, Joy R, Trites AW (2009) Fasting affects the surface and diving metabolic rates of Steller sea lions Eumetopias jubatus. Aquat Biol 8:71-82

> Wang Z, O'Connor TP, Heshka S, Heymsfield SB (2001) The reconstruction of Kleiber's law at the organ-tissue level. J Nutr 131:2967-2970

Williams TM (1999) The evolution of cost efficient swimming in marine mammals: limits to energetic optimization. Philos Trans R Soc Lond B 354:194-201

Willis K, Horning M, Rosen DAS, Trites AW (2005) Spatial variation of heat flux in steller sea lions: evidence for consistent avenues of heat exchange along the body trunk. J Exp Mar Biol Ecol 315:163-175

> Wilson RP, White CR, Quintana F, Halsey LG, Liebsch N, Martin GR, Butler PJ (2006) Moving towards acceleration for estimates of activity-specific metabolic rate in freeliving animals: the case of the cormorant. J Anim Ecol 75: 1081-1090

Young BL, Rosen DA, Hindle AG, Haulena M, Trites AW (2011a) Dive behaviour impacts the ability of heart rate to predict oxygen consumption in Steller sea lions (Eumetopias jubatus) foraging at depth. J Exp Biol 214: 2267-2275

> Young BL, Rosen DAS, Haulena M, Hindle AG, Trites AW (2011b) Environment and feeding change the ability of heart rate to predict metabolism in resting Steller sea lions (Eumetopias jubatus). J Comp Physiol B 181:105-116

\section{Appendix 1.}

To allow comparison with our earlier work (Fahlman et al. 2008c), we mass-corrected the metabolic rates using the mass exponent $\left(M_{\mathrm{b}}{ }^{0.75}\right)$ previously published for Steller sea lions to derive the mass-corrected $\mathrm{MR}_{\mathrm{Sp}}\left(\mathrm{sMR}_{\mathrm{Sp}}=\mathrm{MR}_{\mathrm{Sp}} \times\right.$ $\left.\mathrm{kg}^{0.75}\right), \mathrm{MR}_{\mathrm{S}}\left(\mathrm{sMR}_{\mathrm{S}}=\mathrm{MR}_{\mathrm{S}} \times \mathrm{kg}^{0.75}\right)$ and $\mathrm{MR}_{\mathrm{DI}}\left(\mathrm{sMR}_{\mathrm{DI}}=\mathrm{MR}_{\mathrm{DI}}\right.$ $\times \mathrm{kg}^{0.75}$.

For $\mathrm{sMR}_{\mathrm{Sp}}$, only $\mathrm{ODBA}_{\mathrm{S}}$ warranted inclusion, and the best model was $(\mathrm{p}<0.1, \mathrm{LL}=-138.1, \mathrm{df}=37$, NULL-LL $=$ -139.7 , df = 38):

$$
\mathrm{sMR}_{\mathrm{Sp}}=2.00 \times 10^{-2}+4.96 \times 10^{-2} \times \mathrm{ODBA}_{\mathrm{S}}
$$

Using Eq. A1, the basal metabolic rate in water would be $6.5 \mathrm{ml} \mathrm{O} 2 \mathrm{~min}^{-1} \mathrm{~kg}^{-1}$.

For $\mathrm{sMR}_{\mathrm{DI}}$, ODBA and SR remained in the best model $(\mathrm{p}<0.01, \mathrm{LL}=-927.9, \mathrm{df}=224$, NULL-LL $=-934.1, \mathrm{df}=$ 226):

$$
\mathrm{sMR}_{\mathrm{DI}}=2.0 \times 10^{-2}+2.5 \times 10^{-2} \times \mathrm{ODBA}+9.8 \times 10^{-3} \times \mathrm{SR}
$$

The mean error for the data set was $-2.4 \%$, with a range from -63.8 to $27.6 \%$ (median $-2.5 \%$ ). 